\title{
The Construction of Teacher Identity in an Alternative Education Context
}

\author{
Raymond Brown ${ }^{a}$ and Deborah Heck ${ }^{\text {b* }}$ \\ ${ }^{a}$ School of Education and Professional Studies, Griffith University, Brisbane, Australia.; ${ }^{b}$ \\ School of Education, University of the Sunshine Coast, Sippy Downs, Australia.
}

Raymond Brown Email: ray.brown@griffith.edu.au

Deborah Heck Email: dheck@usc.edu.au

\begin{abstract}
The focus of this article is the construction of teacher identities in an alternative school setting. Using a sociocultural theoretical understanding of 'identity' development based on the notions of 'relational agency' (Edwards, 2007) and 'relational equity' (Boaler, 2008), an adaptation of Burke's (1945) dramatic 'pentad' is used to analyse teacher interview scripts about being and becoming a teacher. Findings suggest that teachers construct multiple identities in an alternative schooling context that are focused on their perceived role within the school - teacher, co-learner, principal. Three formats of teacher identity - replacing, blending, privileging - are offered to explore teacher identity.
\end{abstract}

Keywords: sociocultural; teacher identity; agency; equity; alternative schooling

\section{Introduction}

The notion of identity is difficult to theorise. It cannot be simply reduced to elements such as thinking, emotion, morality, gender, agency, or practice (Roth, 2007). However, researchers often focus on one or two elements of 'identity' to explore, for example, the constrution of student discursive identity in subject disciplines (Kumpulainen \& Rajala, 2017), the development of teacher agency during curriculum reform (Lasky, 2005; Tao \& Gao, 2017), early career teacher emotions (Nichols, Schutz, Rodgers, \& Bilica, 2017), and teacher educator collective professional agency (Hökkä, Vähäsantanen, \& Mahlakaarto, 2017). Each of the above studies has an integrity of its own, and each has provided valuable insights into 
the nature of identity in educational contexts. What each of the above studies is attempting to do is provide a believable account of individuals 'being' in a world that is observable, a world that is constituted of many contexts of activity based on distinctive principles and practices (Roth, 2007).

This article makes a unique contribution to the body of research on 'identity' that precedes it, not because it provides definitive insights into the development of teacher identity, but because it attempts to apply the contributions of research to explore the 'multiple identities' that teachers may construct when engaging with a diversity of colleagues (youth workers, chaplains, etc.) and students within an alternate schooling context. Alternative education in this study is defined as an education context that supports the education of school aged young people who have been pushed or dropped out of mainstream schooling. It attempts to explore the cultural nature of 'being' a teacher in an alternative education community, exploring the notion of 'identity' as it applies to a 'collective' as well as to 'individuals'. This is not to deny the individuality of 'identity', but to foreground the dialectical tension that exists between an individual and a collective, to explore the communal principles and practices that enable the expertise of teachers to reach into the realm of students' personal experiences to promote development. As such, 'identity' is conceptualized in this article as a community-forming process where teachers, other adults and students express and communicate ideas according to a shared set of principles and practices.

Relational agency and relational equity are the theoretical frames used to guide the exploration of the research issue articulated above. Three qualitative interviews with educators from an alternative education context formed the data analysed using the dramatic pendant framework. The results are presented as three stories of educator identities as they talk about their work within an alternative education context. Finally, the discussion of replacing, blending and privileging as three formats of identity that teachers might construct 
in alternative education contexts articulates the potential of the formats as an analytic tool for exploring the construction of teacher identity.

\section{Theoretical Framing}

According to Wertsch (1998), the tension between people and the cultural means (principles and practices) at their disposal results in an on-going process of transformation and creativity that has the potential to not only change the relationship of people to the world by shaping and constraining their participation in it, but also to transform the individual person by incorporating his/her activity into new, functionally active systems that are culturally and historically situated. This interpretation of human development focuses the notion of "teacher identity' as being constructed within the tension that exists between the cultural knowledge available within an instructional context and the everyday knowledge and experience of colleagues and students (Lave \& Wenger, 1991).

The institutional context of schools and classrooms, where such tension between the 'everyday' and the 'cultural' typically occurs, provides powerful messages to both teachers and students about their respective roles in the learning endeavor. For instance, in many mainstream schools, the ideal student is often constructed as a receptive, attentive, and respectful learner who is willing to follow teacher directions and complete assigned tasks to the teacher's satisfaction. The ideal teacher is constructed most often as being a classroom leader who can transmit cultural concepts using efficient and effective methods.

In attempts to challenge these traditional roles, Edwards (2007) employed Cultural, Historical, Activity Theory to incorporate the collective into the individual through the elaboration of a form of relational agency that situates the teacher in relationships with others, relationships centered on dealing with problems embedded within social practices. Relational agency as described by Edwards (2007) is the capacity to work with others in a 
manner that looks for multiple solutions to a problem by bringing to bear the 'sense-making' of others and the resources that they draw upon. In other words, relational agency requires teachers to learn how to recognise and utilise the resources within the workplace, including people, in the transformation of the object of their work (Edwards, 2005; Edwards \& Mackenzie, 2005). It challenges teachers to step beyond generalised assumptions and traditional roles for the sake of a shared purpose.

In a similar vein, Jo Boaler (2008) proposes the term 'relational equity' to challenge the traditional roles of the classroom. Relational equity situates teachers and students within a curriculum that requires teachers and students to treat each other's viewpoints respectfully. That is, having a genuine curiosity about others' perspectives and to give voice to all. It involves principles of social justice such as being able to value diversity, to actively listen to and respect others, and to have a concern for the common good.

Alternative education contexts can be difficult because teachers need to develop and learn new ways to distribute, more symmetrically, authentic roles within the learning endeavor by drawing on the 'funds of identity' of the alternative school context, that is the "historically accumulated, culturally developed, and socially distributed resources" by which, teachers, co-workers and students within an alternative education context define themselves (Esteban-Guitart \& Moll, 2014, p31). Consequently, understanding the construction of identity within an educational context requires an understanding of the "practices, beliefs, knowledge and ideas" that people make use of in that context (Esteban-Guitart \& Moll, 2014, p31). To provide insights into how teachers may ethically move beyond the perceived ideals of an education system for the purpose of educating, the present practices, beliefs, knowledge, and ideas employed within alternative education sites need to be observed in context to explore 'relational agency' and 'relational equity' in practice. As the constructs of 'relational agency', 'relational equity', and 'funds of identity' situate learning and teaching 
within respectful relationships with others embedded within communal practices and principles by which, teachers and students define themselves, 'identity' is conceptualised in this article as a community-forming process where teachers, other adults, and students express and communicate ideas according to a shared set of principles and practices.

\section{Research Design}

\section{Context of the Research}

The research reported here is part of a larger four-year study designed to develop and apply a School Renewal Profiling Tool to provide an evidence-based device for enabling school communities to engage in a learning-based approach to school renewal (author, 2018 [details removed for peer review]. This larger study employed school and classroom observations, interviews and surveys to capture local ways of knowing, doing and valuing as resources to promote organisational renewal through reflecting individual perceptions of participation in collective practice.

The research reported in this article focuses on one education site from the larger study (referred to in this article as Kings) devoted to supporting young people who are experiencing vulnerability, powerlessness and/or poverty because they may be at the margins of society, out-of-home and/or disengaged with education. Kings is a co-educational school where teaching and learning are situated within small classes and a flexible curriculum that draws on student interests. Multi-disciplinary teams work with young people to build selfconfidence and esteem and to develop the knowledge and skills necessary to engage in the development of a fulfilling future. Teaching and learning at Kings is grounded in principles that guide practice such as- respect, participation, safe and legal, and, honesty (see Vadeboncoeur, 2009 for more information). The principles provide a common ground approach that offers a space for young people to re-engage with both their community and 
learning and become empowered to develop their own pathway. These principles are core to the induction of each teacher and student into the school and are constantly referred to in school curriculum and policy documents. In essence, the principles frame the community in which teachers and students operate in a way that respects the agency and rights of all and enables meaningful educational engagement. Although congruent with a Catholic culture of schooling in which this study was conducted the relationship of these principles to Catholicism is not a focus of this study.

Kings was chosen as a focus for this article because it was, at the time of the research, the eldest of 5 alternative education schools and 7 outreach services nested within a larger system of education. This larger system is an independent network of Catholic schools with an enduring history in the development of Catholic Education in Australia. The school at the centre of this research has been operating in a major city for the past 30 years. The school population comprises a diverse range of young people, aged between 12 and 20 years, whose lives evidence difficult circumstances with complex issues affecting their being in the world. These difficult circumstances reflect the instability in the local community due to increasing ice use and chroming, the disintegration of the family unit, regular incarceration and the devaluing of education as a vehicle to change one's life. This school was established for the specific purpose of engaging students with significant histories of non-school attendance through the development of trusting relationships and opportunities to experience success both educationally and socially.

\section{The Participants}

Two teachers (Lisa and Grace) and one administrator (David) agreed to participate in the research. Lisa is a qualified special education teacher who specialises in teaching Numeracy at Kings. She is a long-term member (over ten years) of Kings with little or no experience of 
teaching in a mainstream school. Grace is an overseas trained middle school teacher specialising in the social sciences (History, Film and Television). She has been teaching at Kings for four years and has experience of teaching in mainstream schools. David is the chief administrator of the network of alternative education schools located in the larger system of schools. He is a co-founder of Kings and has been involved with the site for over ten years. Trained as a secondary English teacher, David has experience of teaching in youth detention centres.

\section{Data Collection and Analysis}

The cultural legitimacy of a narrative, in this case teacher stories, rests on the principles upon which the drama of the narrative is based (Bruner, 1991). Drama is used here in the sense of Burke's (1945) dramatic 'pentad' - Agent, Act, Scene, Purpose, Agency - and is used to describe what might be involved when people engage in the work of a collective, in this case an alternative education school, say what they are doing and why they are doing it. Burke's notion of 'scene' provides a useful way of conceptualising the relationship between the practices of the collective and the cultural principles that guide that practice. Using "scene" in the sense of setting, or background and "act" in the sense of action, one could say that "the scene contains the act". Moreover, using "agents" in the sense of actors [in this case teachers] ... one could say that "the scene contains the agents". It is the principle of drama that "the nature of acts and agents [teachers] should be consistent with the nature of scene [collective work of Kings]". . Or, if you will, the stage-set [the collective] "contains the action ambiguously" ... and in the course of the play's development this "ambiguity is converted into a corresponding articulacy" - a common ground of cultural understandings (Burke, 1945, pp. 3-7, words in parenthesis added). 
As a method, Burke's pentad is appropriate to the purpose of this study because it is aimed at addressing the empirical questions of how people explain their actions to themselves and others and is suitable for exploring what the cultural principles and social practices within these explanations might be (Overington, 1977). The principles that form the basis for a common ground of cultural understandings for the alternative education site being investigated include respect, participation, safe and legal, and honesty. These principles form the foundational philosophy that guides practice in the alternative education network and are used within the network to shape the ways teachers and others work with students. The principles are not explicitly defined, thus, to a certain extent their meanings are ambiguous requiring the use of negotiation and dialogue in their interpretation and application.

Observations at Kings included classroom and school observations and in-depth interviews to gain a rich description of the life of the alternative education site. Classroom and school observations were made using an 'observational schedule' that incorporated categories relating to teaching, spirituality, community, and justice (see author, et al., 2018 [details removed for peer review $\}$ ). The purpose of the observation was to provide a framework for researchers to develop a holistic understanding of the context (Foster, 2006). It is the purpose of this article to provide insights into the construction of teacher identity in an alternative education context as teachers talk about their present practices, beliefs, knowledge, and ideas as they go about their work.

Interview questions were designed that related to the 'observational schedule' and took the form of a semi-structured or guided interview (Lichtman, 2014). The general question guide situated the interview questions within broad categories relating to teaching, spirituality, community, and justice. Interviews were conducted by researchers in places where interviewees felt comfortable to tell their stories in accordance with interview protocols (Kvale, 2009). Each of the participants in the study was interviewed once for 
between 30 minutes and one hour. Interviews were audio recorded and transcribed for analysis. The data reported in this article focuses on the three, one hour interview transcripts with three educators at one alternative education school site, Kings. Regarding what Patton (2015) refers to as issues of quality and credibility in qualitative research, participants' interview data were analysed by two researchers who cross-referenced participant responses with classroom/school observations and engaged in ongoing conversations about particular data interpretations where there was disagreement until an agreement was reached. With this in mind, the interview transcripts were analysed using the following thematic framework relating the principles of Kings to the elements of the dramatic 'pentad'. From each teacher's perspective, the following questions were asked (a) Agent: Who do the principles apply to? (b) Act: How are the principles applied? (c) Scene: In what contexts are the principles applied? (d) Purpose: Why are the principles applied? (e) Agency: What was the effect of the application of the principles? The notion of pentad used in the analysis of this study attempts to situate the relationship between the explanatory vocabulary used by participants in their interviews and their reported practices within a context that highlights the relationship between the principles of the alternative education context in which they operate and relational agency and relational equity.

The analysis of the interview transcripts was guided by a form of Interpretative Phenomenological Analysis (IPA). IPA was chosen to guide the analysis as it attempts to 'unravel the meaning contained in accounts through a process of interpretative engagement with the text of transcripts (Smith, 1996, p. 189), and because it can be used within "a range of theoretical perspectives provided that they are developed around a central account of the participants' experiences" (Reid, Flowers, \& Larkin, 2005, p. 20). The analysis of each interview script involved three stages. The first stage of analysis involved generating and 
exploring themes, summaries, questions, use of words, metaphors based on the identification of agent, act, scene, purpose and agency.

The second stage of the analysis involved identifying those themes which captured the essence of what the text displayed. A further review of the interview texts was made with the following specific questions in mind: Agent: Who talks about the principles? Who are referred to as 'deliverers' and 'receivers' of the principles? (ii) Act: How are the principles that underpin the work of the school talked about? How do the forms of talk about the principles differ? (iii) Scene: How is the school described? What kinds of metaphors are used to describe the school? (iv) Purpose: What principles are considered valuable and valued for this cohort of teachers and/or students? Why? What constitutes an effective pedagogic relationship in this context? Why? (v) Agency: How does the teacher measure success? What do the students take away from this school context?

Stage three of the analysis involved connecting themes through considering their relationships and recording a super-ordinate theme that could be expected to emerge from the analysis. To capture a super-ordinate theme emerging from the text, a third examination of the interview texts was made with the following questions in mind: (a) Agent: What metaphor best applies to the person doing the speaking? (b) Act: How are people's lives valued at Kings? (c) Scene: Where does a sense of value come from? (d) Purpose: What is the purpose of this valuing? (e) Agency: How does this valuing relate to people's lives in and outside of school? The formation of these third stage questions was guided by the notion of 'relational agency' that highlights working with others in ways that value the sense-making of others and the resources that they bring to a situation, and by the notion of 'relational equity' that highlights relating to others in ways that value diversity, respect and people's ways of being. The incorporation of 'effect' into Burke's notion of the pentadic element 'agency' is deliberate to focus on the situated nature of learning and the relationships between 
the participants in the study and the specific contexts in which they taught. It also aligns with the ways in which Edward's notion of 'relational agency' (see for example, Edwards \& D'arcy, 2004) and Boaler's concept of 'relational equity' (see for example, Boaler, 2009) are used in research and is in accord with Rountree's (1998) interpretation of Burke's pentad that highlights the overlap between Burke's pentadic terms and pentadic analyses so as to reveal "the strategic spots at which ambiguities necessarily arise" (Burke, 1945: xviii). The analytic framework was designed and chosen for use in this study because it has the potential to provide a believable account of what Roth (2007) refers to as 'being' in a world that is observable.

\section{Results}

Using the dramatic 'pendant' framework, three distinct stories are recounted to explain how each educator experienced the application of the principles in the context of Kings.

\section{Lisa: Teacher vs Shaper of Social Norms}

As an individual, Lisa, sees herself as a teacher, a participant in the learning process, and as a shaper of behaviour. Individuality is conveyed in utterances which refer to herself as having "a pretty broad view of what teaching and learning is. I think I learn as much as they (the students) do. I learn every day from them as well, and I acknowledge that to them, they teach $m e ”$. Her actions are perceived by Lisa as being about facilitating student learning, conveyed through statements such as "with some of our kids the way they talk in their language, that's appropriate in their world and I don't think it's my role to say that's wrong, or you shouldn't swear like that. My role is not to judge, I never have judged the way they operate".

In terms of the context of her teaching, Lisa views her work as mainly happening in the area of behaviour "you know I accept and respect their (students) diversity, that's the way they talk, that's the way they do things, but I do think I have a role to show them that if they 
want access to some other places in life they need to learn some other ways of being as well". She sees the school as being "a place where you are not asked to verbalise it (the principles), you are asked to live it and that can be a real big challenge to live it, because we're challenged every time we (the teachers) don't quite meet them (the principles) either".

For Lisa, teaching at Kings is about helping the students to see themselves "as a learner again. It's about believing in yourself, it's about being willing to take risks", for the purpose of developing "self-control, I think that's probably one of the biggest things we can give them," as gauged by behaviours such as "kids that say sorry and mean it. (That) is a huge success for me”.

As a collective, Lisa views Kings as being made up of "young people that are maybe third generation unemployed" and as catering to some families that are "to all intent and purpose quite dysfunctional at times". As such, Lisa views her role within Kings as being a shaper of social norms. This relationship with the collective is summed up in a story related by Lisa during the interview. According to Lisa, she received a phone call in the office one day from a student, Pete, asking if another teacher, John, was there. Lisa replied that John was not available at the moment and could she please take a message. Pete replied "can you just tell him that 3000 is nowhere near enough, I have to have at least 5, I can't possibly do it on 3000 ”. When asked what he was talking about, Pete explained that he was doing an assignment for John that required him to plan a trip with a budget of $\$ 3000$. Lisa went on to say that "it really struck me. I thought he is going to pass that assignment and he is going to get a good mark for that assignment, and yet he couldn't use the phone properly, he couldn't say to me, it's Pete here can I speak to John, you know have we succeeded?"

In terms of the principles upon which the school is based, Lisa has "actually found that they, the four principles, become a real boundary for them (the students)". Their efficacy revolves around the provision of security and predictability, "it (the school) becomes 
for many of them I think, it's the first place in their life they feel safe and they know the rules, they know exactly what they are and they know exactly what they are going to be asked to do and, that's really important". However, understanding the principles "can take you know, it takes a long time for the young people to actually grasp what those principles mean, but it takes a long time for staff too”.

\section{Grace: Realist vs Co-learner}

As an individual, Grace, sees herself as a realist who identifies with being a practical teacher governed by students' interests and as having concerns about the curriculum direction in which Kings is going. Individuality is conveyed in statements which refer to herself as a 'realist', for example, when discussing issues related to 'racism' at Kings, Grace states, "People don't like talking about it, but it definitely exists, and it exists here. We could be addressing that better than we have. I have ideas on how we could address it. Whether that will happen or not depends on a variety of factors, I am a realist really”.

In terms of the context of her work, being a teacher is important for Grace, but a teacher who "works in such a practical way with these kids" for the purpose of building productive teaching learning relationships, "if I have a group that is interested in skate parks and doing BMX stunts then I have got to follow that because that is a way I can get in. That is a way I can build rapport that is the layer that builds all the other stuff". However, personally Grace is concerned with the level of 'flexibility' in King's curriculum. For example when talking about teaching and learning she states, "I can really see a trend that is quite, quite dangerous for the fundamental way that we care for these kids. We have got to stay flexible. And if I can't do that (teach to the students' interests) because of 'bloody' work place health and safety, then I am in trouble". 
For Grace, teaching at Kings is about imparting to students "things that I think are useful skills for people to have, a list of what is needed, and that's knowledge, skills and attitudes related to life and work". It's about getting students to "hook into learning" by "going for the big concepts, you go for the big questions, you explain for example evolution in three minutes if you like because the base idea is relatively simple. Then if there are people who want to go into it in detail they can do that in an assignment", for the purpose of students "reaching their own goals".

As a collective, Grace views Kings as being made up of " a real group of survivors. And if I was ever in an accident I would like these kids to rescue me, I really would, I trust them. Not indefinitely, and I will definitely check up on a heap of things. But I do trust them to treat me well". As such, Grace views her role within Kings as being a co-learner, one who “actually doesn't particularly care about the past. But in here you do not have to like each other, but if you are in the same class, you must be able to get on and be safe to be with".

This relationship with the collective is summed up in a story related by Grace during the interview about a boy, Sam, that she had been working with and receiving little but 'behavioural issues' in return. According to Grace, “he simply doesn't fit here and I've told him that in those words". Grace uses the metaphor of a mirror to relate the work of the collective, "We're a kind mirror, but we are a mirror that will help again and again, but we are a mirror of what you do and we will show it, with compassion, but we will show it, you can lump it or like it. And some (students) go away and say, and we just think oh well they are not ready to do their own thing and then we feel good about it". For Sam, Grace attempts to find him a place in a 'more mainstream' school, "So I've been pestering him if you like about going to another school, St Henry's, it's in between a total mainstream and us. They have a really nice pastoral care program and they have much more to offer him". 
In terms of the principles upon which the Collective is based, Grace views their efficacy as being "incredibly strong”, but it takes a while "before you can see how much you can do with them”. However, Grace sees the principles themselves as needing protection from the larger system of education in which the alternative school network is situated, "they (system authorities) keep trying to push us into more stricter, less flexible guidelines and we keep resenting it, resisting sorry, that was the wrong word. And there is a definite difference in information levels between those that make the decisions and those that have to do them, and it's really hard to get the right information to the right places, there are no channels for that".

\section{David: Builder vs Bender}

As an individual, David, sees himself as a principal of a learning community, a participant in the community who comes from a similar background to many of the students, and as a role model. Individuality is conveyed in utterances which refer to himself as having an "experience of school similar to many young people who we work with now". His actions toward the students at Kings are perceived by him as being similar to how he would "care for my own child. I employ the same sorts of values and thoughts and sense of love that I would give to anyone else that chooses to be with us".

In terms of the context of his work, David views his work as mainly happening in the area of relationships, "I'm responsible for the, first and foremost, for the setting of culture, and the direction around its relationship with the congregation (the church body that funds the network) and working with those young people that are, or working with those young people that are probably the most disenfranchised in our community". He sees the school as being a place where he and his staff "have been trying for a long time to create a learning environment that is respectful of young people. We try to capture, the cultural capital they 
bring to the place, and to help them realize their potential, and to develop their potential. We (the staff) acknowledge they will come with an enormous amount of learning, and an enormous amount of knowledge and then I would hope that we can develop adults, in a way, that recognizes the solution a person brings to that place".

For David, teaching at Kings is about "building relationships with young people that would help them understand where they can go with the knowledge that they've got and scaffold their learning, so the adults (teachers and youth workers) learn as much as the young people in the process", for the purpose of developing "pathways of how you (the student) want to live your life". As a collective, David views Kings as being made up of "those young people that are probably the most disenfranchised in our community". David views his leadership role within this collective as being a role model who, at times, talks with students "as an equal", but when necessary "at some points during the day I would be not an equal. I have the authority to bend the relationship, and on some occasions I have to do that".

David believes that Kings "is about supporting them (the students) to live their lives in how they're going to participate, to be respectful, to have respect, to be safe and to try and be honest". The efficacy of Kings revolves around the provision of a quality future and engagement, "a quality future, it's about engaging in the wider community, engaging in the politics of the wider community. It's about being an active citizen, about critiquing, you know, saying that this is wrong. Young people come to us as, have found themselves in the system that doesn't work for them for complex reasons, and they have decided to stand up against it and find something that actually works, so in a sense we're political ambassadors within that environment".

David sees the school in terms of the principles upon which the school is based, "those four principles that we operate by". The efficacy of the relationship between the 
school and the principles is summed up in a story related by David during the interview. According to David, "I know one young woman years later, working with us, was in a domestic violence relationship with her partner who was hurting her, so she used the four principles and wrote them down on a piece of paper and stuck them around the house, and said this is how we are going to be together. And you know for six months or so he stopped behaving that way and she kept coming back to using those words to support their conversation around being together. So that's kind of a practical expression of how people internalize that (the principles) and use it (the principles) in their lives". However, living the principles at Kings requires a choice by students and "when we've got a very complicated situation around issues of conflict, or tension issues, a young person might need to transition from us because they might have overstepped the boundaries of a principle to the point of where we can continue to support them".

\section{Analysis}

This article set out to provide insights into the construction of teacher identity in an alternative education school. These stories evidence that how teachers talk about their practices, beliefs, knowledge, and ideas as they go about their work can be very different. For Lisa, her identity within Kings was very teacher-centric, based on rule following, social norms related to acting and speaking, self-belief, and self-control. The boundary between teacher and student is well defined and fixed, couched in terms and phrases which refer to students and their families as being "them out there", who have 'dysfunctional' ways of being that need to be disconnected from if students want to have access to the world of opportunities. Lisa sees herself as a learner, a team member who often has to switch roles between teaching curriculum content and modeling and explaining social norms. Overall, for Lisa, being at Kings is mediated by the principles -, respect, participation, safe and legal, 
and, honesty - which situate both staff and students as learners and, to some extent, followers focused on what is and what 'should be' rather than on what 'could be'.

On the other hand, Grace is a participant in the learning at Kings focused more on what 'could be' rather than what 'should be'. For Grace her identity within Kings was student-centric, based on student interests, being able to get on with others, to be safe to be around, mirroring appropriate behaviour, and 'fitting' in. The boundary between teacher and student is not well defined nor fixed, couched in terms and phrases which refer to students as, 'survivors', 'rescuers', deserving of limited 'trust', and as requiring knowledge, skills and attitudes related to life and work. For Grace, being at Kings is mediated by the principlesrespect, participation, safe and legal, and honesty- which guide both staff and students in how to 'fit' within the community of Kings. Overall, Grace sees herself as a 'realist', a 'colearner' in the school who, to some extent, is in conflict with the vision of schooling being advocated by system authorities. One system authority that Grace would appear to be in conflict with is David.

For David, his identity within Kings was leadership centric, based on an egalitarian relationship with staff and students that can be 'bent' when necessary to preserve the four principles that support the culture of the school. The boundary between his role as principal and teacher is not well defined and couched in terms and phrases related to facilitating a 'quality future', 'community engagement', 'active citizenship', and 'political ambassadorship'. The boundary between his leadership role and students is also not well defined, being couched in terms and phrases related to 'speaking as an equal', 'choosing to participate', 'value adding' to student capital, and everyone being a 'learner'. However, a clear boundary exists between himself and students when he needs to take on an authority role within the collective as the responsible leader. For David, being at Kings is built upon the principles - respect, participation, safe and legal, and, honesty- which guide the practices 
of those staff and students who choose to be at Kings. Overall, David sees himself as being a model of behaviour and as being an equal to others in a collective of disenfranchised learners and value adders tasked with the responsibility of being political ambassadors for change.

In terms of the 'dramatic pentad', all three participants, Lisa, Grace and David perceived that the four principles that formed the foundation of their work at Kings applied to everybody - teachers, other staff, students and members of the community involved with Kings. From the above analyses, it can be seen that all three participants felt that the four principles are applied through discussion and negotiation, not only in complex contexts that involve issues of conflict, or tension, but also in the daily living of the work at Kings, although for David, these contexts extend to marital and family relationships.

However, the purpose for applying the principles differs for each participant. For Lisa, the principles facilitate student appropriation of rules and social norms, for example, those associated with making a phone call, rules and norms associated with the wider societies' ways of speaking and behaving. For Grace, the purpose is to facilitate student 'fit' with the culture of the local school, a culture that acts like a mirror allowing students to see themselves as they really are. For David, the purpose is to assist staff and students on their journeys to becoming political ambassadors for change, ambassadors who have rejected mainstream forms of education and who have decided to stand against it and find a system of education that actually works. As such, success at Kings is gauged differently by each participant. For Lisa, success is about the student seeing themselves as a learner again; it is about behaving yourself and being in control. For Grace, it is about students appropriating the knowledge, skills and attitudes related to life and work so that they can achieve their own goals. For David, it is about supporting staff and students to live their lives and to participate in society in ways that are respectful, safe and honest. 


\section{Discussion}

This article explores the cultural nature of 'being' a teacher in an alternative education community. The characteristics that we aim to highlight and discuss focus on the categories of the 'dramatic pentad' as teachers talk about their work in their particular alternative school context. The diversity of staff roles in alternative schools can be a point of difference to staffing in mainstream schools where the role of the teacher is the primary and dominant role. Working collaboratively in what can be, at times, stressful contexts requires a set of skills not always privileged in mainstream school settings (Hanson-Peterson, 2013). The context of mainstream schooling has often not provided this collaborative context for young people and has often led to disengagement of students with their community and schooling. Therefore, it is not surprising, that teachers in alternative school settings describe themselves in ways that have a core of their becoming a teacher embedded in relationships.

\section{Identity and school role}

The self-portrait supplied by Lisa suggests that she is unaware of the funds of identity (for example, her hegemonic view of the world) which are mediating her being a teacher at Kings. In many ways, it appears that Lisa has enacted many of the elements of relational equity with her students such as respect for difference and the provision of care and support. However, respecting difference is not the same as 'judging the way people operate'. According to Boaler (2008), respect for difference includes having a commitment to the learning of others and to the different ideas and viewpoints they bring to the teachinglearning relationship. It would appear that Lisa's commitment to the learning of others and their view of the world is dependent on students' willingness to 'fit in' to her view of the world.

On the other hand, Grace seems committed to incorporating the knowledge, beliefs and points of view of students into her teaching and learning. It is clear from the analyses that 
Grace privileges this arrangement. Being a teacher for Grace seems to be about being a colearner with the students. Elements of relational agency such as collaboration, motivation, and mentoring (Edwards, 2007) are clearly evident in her interview script.

Relationships in Grace's classroom seem dependent on students 'fitting in' with the culture of Kings as expressed through adherence to the four principles. The metaphor of a 'mirror' as invoked by Grace suggests that the process by which students come to an understanding of their 'fit' with Kings involves students being asked to stand back from their behaviours and to consider what they are doing in the light of the four principles. This approach is in line with the method of communication and support that are a foundation for the development of relational equity (Boaler, 2008).

The self-portrait supplied by Grace in her interview script would suggest that she is aware of the funds of identity (for example, her attitudes towards workplace health and safety) which are mediating her being a teacher at Kings. In many ways, it appears that Grace has enacted many of the elements of relational agency and equity with her students. However, Grace's utterance that there is a list of knowledge, skills, and attitudes needed to succeed in life and work suggests that the funds of identity that she brings to Kings is somewhat more relevant than the funds of identity brought by students to the development of a shared understanding of the four principles.

In addition, Grace's enactment of relational agency and equity does not seem to extend to the leadership of the system of education that houses Kings. The respect and trust that Grace places in the leadership of Kings seems dependent on the provision of a flexible curriculum that will basically allow Grace to care for her students. Confining the provision of 'care' within an attitude that resists the funds of identity that the leadership bring to the school (for example, knowledge relating to creating safe and healthy workplaces) runs the 
risk of diminishing Grace's commitment to the learning of others, an important element of relational equity (Boaler, 2008).

A participant at Kings who seems to have an approach to relationships that expands the object of teaching to include the thoughts and actions of others is David. Being a teacher who attests to sharing a similar background to the students of Kings, socialising students into ways of being that enable them to function in a world that they have previously rejected seems secondary to enabling the students and staff of Kings to become political activists for change. David seems to embody the idea that the principles of participation, respect, safe and legal, and honesty be interpreted differently by different people to suit the context of the interaction that is being undertaken. By privileging context, David supports an assumption of relational agency, that the negotiations and reconfiguring of understandings, take place on a daily basis within a particular context. For example at Kings, teaching and learning occupies a space that demonstrates a relationship between a focus on learning as enhancing individual achievement and a focus on learning as bringing about systemic change, an in-between space productive of bringing about world transformation (Edwards, 2007).

The self-portrait supplied by David in his interview script would suggest that he is aware of the funds of identity (for example, his social justice view of the world) which are mediating his being a leader at Kings. In many ways, it appears that David has enacted many of the elements of relational equity with the staff and students at Kings, such as respect for difference. However, care and support for difference seem to have its boundaries as implied by David's reference to bending his relationships with students to ensure a balance is maintained between providing care and support for an individual and providing care and support for the collective of Kings. Achieving this balance is necessary to ensure that the agency of the individual is given meaning, in the light of the work of the collective, an important element of relational equity (Boaler, 2008). 


\section{Teacher identity in alternative education contexts}

This article explores the 'multiple identities' that teachers may construct when engaging with a diversity of colleagues (youth workers, chaplains, etc.) and students within an alternate schooling context. Identity and its related dimensions are pervasive of everyday work (Roth, 2007). If we adopt Roth's (2007) assumption that actions and the motivation to act express identities, using Kings as the background, or scene, if you like, it can be implied from the above analyses that the collective work of Kings contains and is comprised of the actions of its actors, individuals such as Linda, Grace and David. However, it is somewhat ambiguous as to what degree Linda, Grace, and David's actions are consistent with the nature of the collective work of Kings. This may be because the drama that is being played at Kings on a daily basis has yet to run its course. What can be said is that the construction of identity at Kings is both mediated by interpersonal relations, but regulated by individual funds of identity. These funds of identity as revealed by the analysis of Linda, Grace and David's interview texts can be summarised under the overarching formats of replacing, blending and privileging as outlined in the sections below.

\section{Replacing}

Lisa provides an example of identity formation that is initially concerned with the perspectives, language and values that students bring with them into the classroom, but these seem to provide but a temporary bridge into forms of speaking and thinking that Lisa deems appropriate. This requires students to work within a system of perceptions and values with its own logic and set of meanings, rather than to oscillate between their everyday funds of identity that they bring to the classroom and Lisa's hegemonic view of the world. Within this practice, it is the voice of Lisa that dominates. The process of identity formation is represented as being fixed, and the role of the teacher is to replace students' everyday ways of being with the norm. 


\section{Blending}

On the other hand, Grace provides an example of identity formation that is initially concerned with populating the learning of the classroom with students' own purposes, for example, those relating to personal interest, challenge, and perseverance. This requires students to work with the teacher to weave their ways of knowing and being with those privileged by Grace into a form of being that reflects the culture of schooling in which they are situated. This blending can occur at a number of levels. For example, it may occur at a level where students' interests may simply be blended with the curriculum that is being taught. It may also occur at a more personal level where students' individual funds of identity are blended with the funds of identity privileged by the local community, for example, Kings. The blending of different funds of identity in the classroom appears productive in enabling students to appreciate the relevance of coming to 'know' and 'do' school tasks and in the construction of a local hybrid form of knowing (Esteban-Guitart \& Moll, 2014).

\section{Privileging}

While similar to, but different from, Lisa and Grace, David provides perhaps another example of identity formation, a contextual privileging form of identity formation that highlights the situational and context-specific grounds for privileging one type of being over another. It is not that some forms of being are qualitatively better in some general sense, but rather that students are urged to adopt certain ways of knowing and doing because they are appropriate to the particular setting with its assumed principles for participation. The important aspect of this form of identity formation is not just the use of students' funds of identity to mediate the learning process, but the use of context-based arguments to justify ways of being appropriate to the context of school and classroom. This is a sophisticated understanding of identity formation that entails judging the worth of a person's ways of 
being, not according to a hegemonic view of the world, but on the relevance of their funds of identity to a particular setting.

\section{Conclusion}

Regarding the cultural milieu which is Kings, it can be said that teachers take on 'multiple identities' when engaging with the diversity of colleagues and students. Our analyses highlight the concord of 'identity forms' that teachers may adopt, that is, the ways of knowing and being that characterise the practices and principles of the collective. On the whole, the practices and principles of Kings are not primarily focused on replacing, blending or privileging one practice or value with another, but on eliciting and communicating diverse ways of being a teacher and a student. Participation in such a concord format of identity formation can be said to be marked by teachers and students placing multiple representations of their selves out in the open for consideration by others. Each representation is offered from a specific fund of identity that may be drawn from living in various communities, thus in the exploration of the identities that teachers form in an alternative education context, it can be said that there is an acceptance of diverse alternative ways of being depending on the chosen stance(s) of the teacher (for example, that of a teacher, co-learner, principal, etc.). It is our belief that formats of being, such as replacing, blending and privileging, provide an analytic tool for analysing teacher identity formation in a manner that permits identity construction within the alternative school to be theorised in terms of relational agency and equity.

The research recorded here complements the work of researchers such as EstebanGuitart \& Moll (2014) by presenting the simple finding that teachers working in alternative school contexts construct multiple identities. The challenge for teacher professional development and teacher education is to identify what these identities might be and to communicate to system authorities, university educators and pre-service teachers the value of 
each of these identities and how they might work together to establish productive relationships within alternative education schools. Developing relationships is a process fraught with difficulties for teachers within alternative education sites where they manage a wide range of issues such as poor literacy and numeracy skills, student attendance, health concerns and often poor public representations of their student populations. The formats of teacher identity that we have articulated here provide teachers and researchers with a resource to design and investigate education contexts that invite such multi-constructions of teacher identity for the purpose of promoting greater participation by students in the curriculum domains of alternative education.

\section{References}

Boaler, J. (2008). Promoting 'relational equity' and high mathematics achievement through an innovative mixed-ability approach. British Educational Research Journal, 34(2), 167194. doi:10.1080/01411920701532145

Boaler, J. (2009). Equity and high achievement: The case of Railside School. In D. Corcoran, T. Dooley, S. Close, \& R. Ward (Eds.), Proceedings of the Third National Conference on Mathematics Education MEI3 (pp. 2-19). Dublin: MEI.

Bruner, J. (1991). The narrative construction of reality. Critical Inquiry, 18(1), 1-21.

Burke, K. (1945). A grammar of motives. Berkeley, CA: University of California Press.

Edwards, A. (2005). Let's get beyond community and practice: the many meanings of learning by participating. The Curriculum Journal, 16(1), 49-65. doi:10.1080/0958517042000336809

Edwards, A. (2007). Relational agency in professional practice: A CHAT analysis. Actio: An International Journal of Human Activity Theory, 1, 1-17.

Edwards, A., \& D'Arcy, C. (2004). Relational agency and disposition in sociocultural accounts of learning to teach. Educational Review, 56(2), 147-155. doi:10.1080/0031910410001693236

Edwards, A., \& Mackenzie, L. (2005). Steps towards participation: the social support of learning trajectories. International Journal of Lifelong Education, 24(4), 287-302. doi:10.1080/02601370500169178

Esteban-Guitart, M., \& Moll, L. C. (2014). Funds of identity: A new concept based on the funds of knowledge approach. Culture \& Psychology, 20(1), 31-48. doi:10.1177/1354067X13515934

Foster, P. (2006). Observational research. In R. Sapsford \& V. Jupp (Eds.), Data collection and analysis (2 ed., pp. 58-92). London: SAGE Publications Ltd. Retrieved from http://methods.sagepub.com/book/data-collection-and-analysis. doi: $10.4135 / 9781849208802$

Hanson-Peterson, J. (2013). Do teacher training programs equip teachers with skills to teach disengaged students?: A preliminary scan. Retrieved from Brotherhood of St Laurence website https://www.bsl.org.au/research/ 
Hökkä, P., Vähäsantanen, K., \& Mahlakaarto, S. (2017). Teacher educators' collective professional agency and identity - Transforming marginality to strength. Teaching and Teacher Education, 63(Supplement C), 36-46. doi:10.1016/j.tate.2016.12.001

Kumpulainen, K., \& Rajala, A. (2017). Dialogic teaching and students' discursive identity negotiation in the learning of science. Learning and Instruction, 48, 23-31. doi:10.1016/j.learninstruc.2016.05.002

Kvale, S. (2009). InterViews: Learning the craft of qualitative research interviewing (2nd ed.. ed.). Los Angeles: Sage Publications.

Lasky, S. (2005). A sociocultural approach to understanding teacher identity, agency and professional vulnerability in a context of secondary school reform. Teaching and Teacher Education, 21(8), 899-916. doi:10.1016/j.tate.2005.06.003

Lave, J., \& Wenger, E. (1991). Situated learning: Legitimate peripheral participation. Cambridge, UK: Cambridge University Press.

Lichtman, M. (2014). Qualitative research for the social sciences. London: SAGE Publications.

Nichols, S. L., Schutz, P. A., Rodgers, K., \& Bilica, K. (2017). Early career teachers' emotion and emerging teacher identities. Teachers and Teaching, 23(4), 406-421. doi:10.1080/13540602.2016.1211099

Overington, M. A. (1977). Kenneth Burke and the method of dramatism. Theory and Society, 4(1), 131-156.

Patton, M. Q. (2015). Qualitative research \& evaluation methods (4th ed.). Thousand Oaks, CA: Sage Publications.

Reid, K., Flowers, P., \& Larkin, M. (2005). Exploring lived experience. Psychologist, 18(1), 20-23.

Roth, W.-M. (2007). Emotion at work: A contribution to third-generation Cultural-Historical Activity Theory. Mind, Culture, and Activity, 14(1-2), 40-63. doi:10.1080/10749030701307705

Rountree, J. (1998). Coming to terms with Kenneth Burke's pentad. American Communication Journal, 1(3).

Smith, J. A. (1996). Beyond the divide between cognition and discourse: Using interpretative phenomenological analysis in health psychology. Psychology \& Health, 11(2), 261271. doi:10.1080/08870449608400256

Tao, J., \& Gao, X. (2017). Teacher agency and identity commitment in curricular reform. Teaching and Teacher Education, 63(Supplement C), 346-355. doi:10.1016/j.tate.2017.01.010

Vadeboncoeur, J. A. (2009). Spaces of difference: The contradictions of alternative educational programs. Educational Studies, 45(3), 280-299. doi:10.1080/00131940902910974

Wertsch, J. V. (1998). Mind as action. Oxford: Oxford University Press.

Author, (2018). [details removed for peer review] 